\title{
The Novel Angiotensin II Receptor Blocker Azilsartan Medoxomil Ameliorates Insulin Resistance Induced by Chronic Angiotensin II Treatment in Rat Skeletal Muscle
}

\author{
Guido Lastraa, c Fernando R. Santos ${ }^{\mathrm{e}}$ Payam Hooshmand $^{\mathrm{e}}$ \\ Paria Hooshmand $^{e}$ Irina Mugerfeld ${ }^{a}$ Annayya R. Aroor ${ }^{a, c}$ \\ Vincent G. DeMarco ${ }^{a-c}$ James R. Sowers ${ }^{a-d}$ Erik J. Henriksen ${ }^{e}$ \\ Departments of a Internal Medicine and ${ }^{b}$ Medical Physiology and Pharmacology, ${ }^{c}$ Diabetes \\ and Cardiovascular Laboratory, and dHarry S. Truman Veterans Affairs Medical Center, \\ University of Missouri School of Medicine, Columbia, Mo., and eDepartment of Physiology, \\ University of Arizona College of Medicine, Tucson, Ariz., USA
}

\section{Key Words}

Angiotensin II · Glucose transport · Red skeletal muscle · Akt · AS160 · AMPK · p70 S6K1

\begin{abstract}
Angiotensin receptor (type 1) blockers (ARBs) can reduce both hypertension and insulin resistance induced by local and systemic activation of the renin-angiotensin-aldosterone system. The effectiveness of azilsartan medoxomil (AZIL-M), a novel imidazole-based ARB, to facilitate metabolic improvements in conditions of angiotensin II (Ang II)-associated insulin resistance is currently unknown. The aim of this study was to determine the impact of chronic AZIL-M treatment on glucose transport activity and key insulin signaling elements in red skeletal muscle of Ang II-treated rats. Male Sprague-Dawley rats were treated for 8 weeks with or without Ang II (200 $\mathrm{ng} / \mathrm{kg} / \mathrm{min}$ ) combined with either vehicle or AZIL-M (1 mg/kg/day). Ang II induced significant $(p<0.05)$ increases in blood pressure, which were completely prevented by AZIL-M. Furthermore, Ang II reduced insulin-mediated glucose transport activity in incubated soleus muscle, and AZIL-M co-treatment increased this parameter. Moreover, AZIL-M treatment of Ang II-infused animals increased the absolute phosphorylation of insulin signaling molecules, including Akt [both $\operatorname{Ser}^{473}(81 \%)$ and $\operatorname{Thr}^{308}(23 \%)$ ] and AS160 $\mathrm{Thr}^{642}(42 \%)$, in red gastrocnemius muscle frozen in situ. Absolute AMPK $\alpha\left(\mathrm{Thr}^{172}\right)$ phosphorylation increased (98\%) by AZIL-M treatment, and relative $\mathrm{Thr}^{389}$ phosphorylation of $\mathrm{p} 70 \mathrm{~S} 6 \mathrm{~K} 1$, a negative regulator of insulin signaling, decreased (51\%) with AZIL-M treatment. These results indicate that ARB AZIL-M improves the in vitro insulin action on glucose transport in red soleus muscle and the functionality of the Akt/AS160 axis in red gastrocnemius muscle in situ in Ang II-induced insulin-resistant rats, with the latter modification possibly associated with enhanced AMPK $\alpha$ and suppressed p70 S6K1 activation.
\end{abstract}




\section{CardioRenal Medicine}

\begin{tabular}{l|l}
\hline \multicolumn{2}{l}{ Cardiorenal Med 2013;3:154-164 } \\
\hline DOI: $\underline{10.1159 / 000353155}$ & $\begin{array}{l}\text { ( 2)13 S. Karger AG, Basel } \\
\text { www.karger.com/crm }\end{array}$ \\
\hline
\end{tabular}

Lastra et al.: The Novel Angiotensin II Receptor Blocker Azilsartan Medoxomil Ameliorates Insulin Resistance Induced by Chronic Angiotensin II Treatment

\section{Introduction}

Type 2 diabetes mellitus and hypertension are powerful risk factors for cardiovascular disease. Systemic and skeletal muscle insulin resistance is often present in both conditions [1-3]. Insulin resistance is widespread in the United States, with an estimated 70 million Americans presenting with this condition [3]. Systemic and tissue overactivation of the reninangiotensin-aldosterone system (RAAS) can play an important role in the development of insulin resistance in skeletal muscle [3-5], the primary site for insulin-mediated glucose disposal in humans [6, 7]. Several lines of evidence from animal model and human clinical investigations support a direct role of angiotensin II (Ang II) action to induce insulin resistance in skeletal muscle. Systemic delivery of Ang II in animal models is associated with defects in both vascular delivery of glucose and insulin to skeletal muscle [8] and with impairment of the glucose transport system in this tissue [9]. Direct treatment of rat skeletal muscle with Ang II leads to impaired Akt signaling and impaired insulin-mediated glucose transport [10]. Moreover, blockade of the RAAS at any of several stages leads to amelioration of insulin-resistant states in rodents characterized by RAAS overactivation, including direct renin inhibition [11,12], angiotensin converting enzyme inhibition [reviewed in 4, 13], Ang II type 1 receptor (AT1R) blockers (ARBs) [14-16], and mineralocorticoid receptor blockade [17]. In the clinical setting, ARBs may have a beneficial impact on insulin resistance and glucose dysregulation $[13,18,19]$.

Azilsartan medoxomil (AZIL-M) is a relatively new and novel imidazole-based ARB that is highly selective for the AT1R and has proven efficacy in the treatment of hypertension [20, 21]. In addition, recent studies suggest that AZIL or AZIL-M improves whole-body insulin sensitivity in rodent models of hypertension, obesity, and insulin resistance [22,23]. However, the impact of this ARB on skeletal muscle insulin sensitivity in an Ang II-induced insulin resistance model has not been previously explored.

In the context of this information, the primary purpose of the present investigation was to assess the impact of chronic treatment with AZIL-M on insulin regulation of skeletal muscle glucose transport activity in a rat model of Ang II-induced hypertension and insulin resistance. To this end, young, male Sprague-Dawley rats were chronically infused with Ang II with or without simultaneous treatment with AZIL-M. Measures of blood pressure as well as ex vivo assessments of glucose transport activity in isolated soleus muscle and cellular signaling via Akt, AS160, AMPK, and p70 S6K1 in red gastrocnemius muscle in situ were made.

\section{Methods}

Animals and Treatments

All procedures were approved by the University of Missouri Animal Care and Use Committee, and animals were housed in accordance with National Institutes of Health guidelines. Male Sprague-Dawley rats were received from Harlan (Indianapolis, Ind., USA) at 8 weeks of age and were treated for 8 weeks by subcutaneous osmotic mini-pump with or without Ang II (200 ng/ kg/min) combined with either vehicle or AZIL-M $(1 \mathrm{mg} / \mathrm{kg} /$ day). Venous plasma samples were taken at the end of the treatment period following a 5-hour fast (beginning at 4:30 a.m.). Plasma glucose levels were measured by an automated hexokinase glycerol6-pyruvate dehydrogenase assay, and insulin levels were assessed using an ELISA kit specific for rat insulin (Alpco Diagnostics, Salem, N.H., USA), as previously described [24].

\section{Telemetry and Blood Pressure Monitoring}

Ambulatory blood pressures were measured following the placement of catheters attached to radio transmitters (TA11PA-C40; Data Sciences International, St. Paul, Minn., USA) in the carotid artery of a subset of the rats, as described previously [25]. As rodents are normally active nocturnally, blood pressure measurements were taken during both the dark (active) and light (non-active) cycles. 
Lastra et al.: The Novel Angiotensin II Receptor Blocker Azilsartan Medoxomil

Ameliorates Insulin Resistance Induced by Chronic Angiotensin II Treatment

Table 1. Body weights and fasting plasma glucose and insulin values following treatment with Ang II without and with AZIL-M

\begin{tabular}{llll}
\hline Group & Final body weight, $g$ & Glucose, $\mathrm{mg} / \mathrm{dl}$ & Insulin, ng/ml \\
\hline Control & $556 \pm 32$ & $130.3 \pm 4.3$ & $2.02 \pm 0.44$ \\
Ang II-treated & $476 \pm 46$ & $140.3 \pm 8.7$ & $1.29 \pm 0.30$ \\
Ang II + AZIL-M & $483 \pm 21$ & $128.8 \pm 2.1$ & $0.82 \pm 0.16$ \\
\hline
\end{tabular}

Values are means \pm SE for 4-8 animals per group. The p value for the comparison of fasting plasma insulin between the control and Ang II-treated groups was 0.092 .

Assessment of Muscle Glucose Transport Activity in Isolated Soleus Muscle

Soleus muscles were surgically removed and prepared into 2 paired strips (approx. 30-40 mg). The muscles were incubated for $45 \mathrm{~min}$ at $37^{\circ} \mathrm{C}$ in $3 \mathrm{ml}$ of oxygenated $\left(95 \% \mathrm{O}_{2}-5 \% \mathrm{CO}_{2}\right.$ ) Krebs-Henseleit buffer (KHB) containing $8 \mathrm{~mm}$ of glucose, $32 \mathrm{~mm}$ of mannitol, and $0.1 \%$ of BSA (Sigma Aldrich, St. Louis, Mo., USA). One soleus strip of the pair was incubated in the absence of insulin, and the other strip in the presence of a maximally effective concentration of insulin ( $5 \mathrm{mU} / \mathrm{ml}$; Novo Nordisk, Bagsværd, Denmark). Following the initial incubation, soleus muscles were transferred for 10 min into $3 \mathrm{ml}$ of an oxygenated $37^{\circ} \mathrm{C} \mathrm{KHB}$ rinse containing $40 \mathrm{~mm}$ of mannitol, $0.1 \%$ of BSA, and insulin, if present previously. Subsequently, the muscles were transferred for $20 \mathrm{~min}$ to $2 \mathrm{ml}$ of oxygenated KHB containing $1 \mathrm{mM}$ of 2 -deoxy-[1,2- $\left.{ }^{3} \mathrm{H}\right]$-glucose (300 $\mathrm{mCi} / \mathrm{mmol}$; Perkin-Elmer, Boston, Mass., USA) and $39 \mathrm{~mm}$ of $\left[\mathrm{U}-{ }^{14} \mathrm{C}\right] \mathrm{mannitol}(0.8 \mathrm{mCi} / \mathrm{mmol}$; Sigma Aldrich), $0.1 \%$ of BSA, and insulin, if present previously. Following this final incubation, the muscles were trimmed of connective tissue, frozen in liquid nitrogen, weighed, and dissolved in $0.5 \mathrm{ml}$ of $0.5 \mathrm{~N} \mathrm{NaOH}$ at $55^{\circ} \mathrm{C}$. After the muscle was completely dissolved, $5 \mathrm{ml}$ of scintillation cocktail were added, and the intracellular accumulation of the glucose analog 2-DG was measured as described previously [26]. This method for assessing glucose transport activity in isolated muscle has been validated [27].

Determination of Cell Signaling Functionality and Protein Expression in Red Gastrocnemius in situ

A portion of the red gastrocnemius muscle was removed, frozen in liquid nitrogen, and stored at $-80^{\circ} \mathrm{C}$ until use. This muscle was homogenized in $8 \mathrm{vol}$ of cold lysis buffer. Homogenates were placed on ice and then centrifuged at $13,000 \mathrm{~g}$ for $10 \mathrm{~min}$ at $4{ }^{\circ} \mathrm{C}$. Total protein assay was performed using the BCA method (Sigma Chemical). Phosphorylation of Akt Ser ${ }^{473}$ and $\mathrm{Thr}^{308}$, AS160 $\mathrm{Thr}^{642}$, AMPKo Thr ${ }^{172}$, and p70 S6K1 $\mathrm{Thr}^{389}$ was assessed by immunoblotting using commercially available antibodies (Cell Signaling Technology, Danvers, Mass., USA), as described previously [16]. Total protein expression of these signaling factors and for pan-actin (all antibodies from Cell Signaling Technology) was also determined.

\section{Statistical Analysis}

All values are expressed as means \pm SE. When multiple groups were compared, a two-way repeated measures ANOVA with a Holm-Sidak post hoc test was used. The significance of differences between two groups was assessed by an unpaired Student t test. A p value of less than 0.05 was considered statistically significant.

\section{Results}

\section{Body Weights, Plasma Glucose and Insulin, and Blood Pressure Responses}

There were no significant differences in final body weight between the control group, the group treated with Ang II alone, and the group treated with both Ang II and AZIL-M (table 1).

Fasting plasma glucose in the Ang II-treated group was not different from the control group value. Unexpectedly, fasting plasma insulin tended to be $36 \%$ lower ( $p=0.092)$ in the Ang II-treated group compared to control (table 1). AZIL-M treatment of the Ang II-infused animals caused a further non-significant decrease in fasting plasma insulin (table 1). 


\section{CardioRenal Medicine}

Lastra et al.: The Novel Angiotensin II Receptor Blocker Azilsartan Medoxomil

Ameliorates Insulin Resistance Induced by Chronic Angiotensin II Treatment

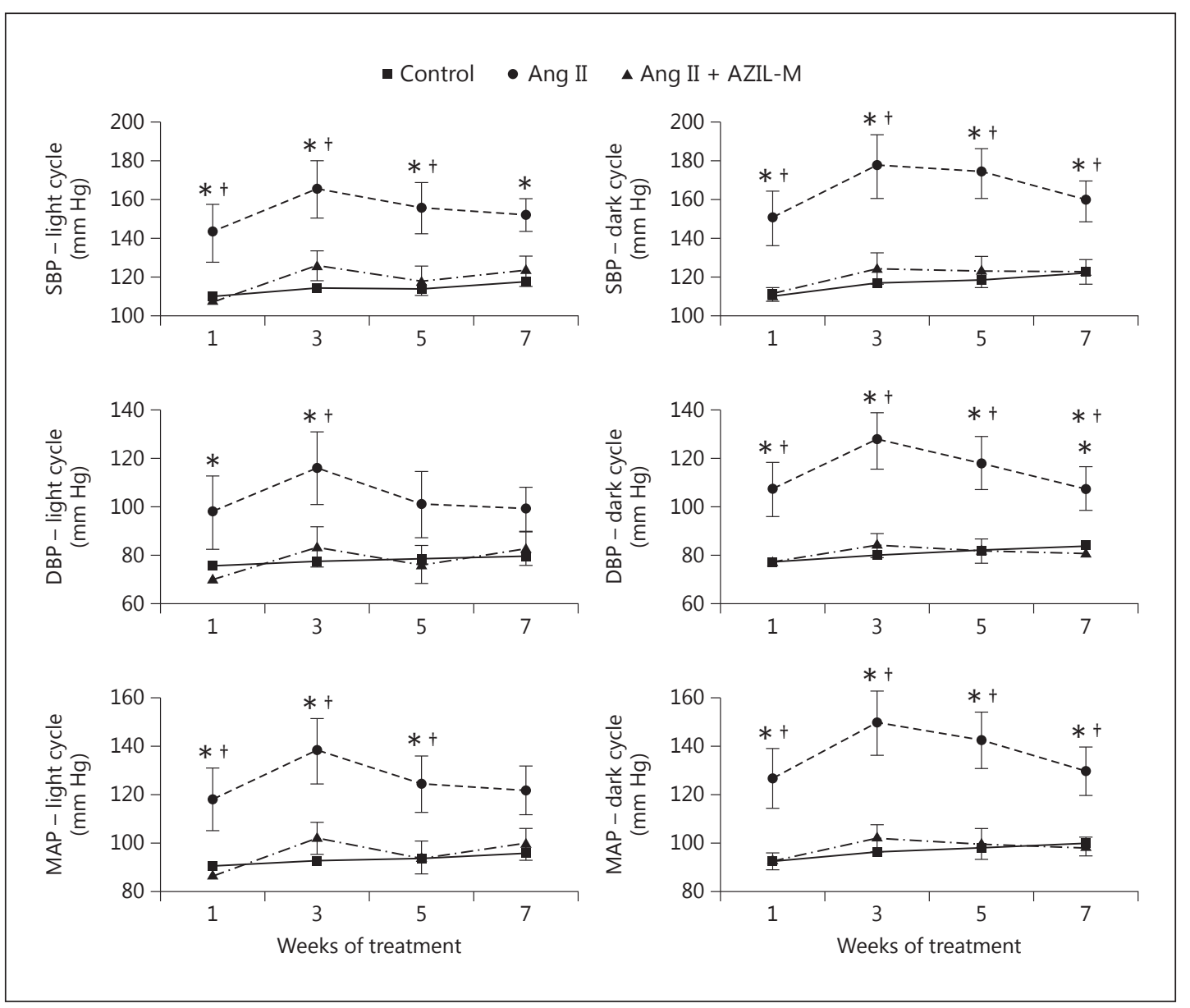

Fig. 1. Effect of Ang II without or with AZIL-M co-treatment on radiotelemetric blood pressure measurements. Values are expressed as mm Hg, and are means \pm SE for 5-6 animals per group. SBP = Systolic blood pressure; DBP = diastolic blood pressure; MAP = mean arterial blood pressure; Ang II = Ang II-treated animals; Ang II + AZIL-M = animals treated with both Ang II and AZIL-M. ${ }^{*} \mathrm{p}<0.05$ versus control group; ${ }^{\dagger} \mathrm{p}<$ 0.05 versus AZIL-M.

Ang II treatment induced significant $(\mathrm{p}<0.05)$ increases in systolic, diastolic, and mean arterial blood pressures, both in the light and dark cycles (fig. 1). These Ang II-induced increases in blood pressure were completely prevented by the co-treatment with AZIL-M.

\section{Effect of Ang II Treatment on Glucose Transport Activity in Isolated Soleus and Cellular}

Signaling in Red Gastrocnemius in situ

Following the 8-week treatment with Ang II, the insulin-mediated increase in glucose transport activity above basal in the isolated soleus muscle was reduced by more than $50 \%$ (though this was not statistically significant, $p=0.125$ ) compared to the control group (fig. 2 ), indicating a state of Ang II-induced insulin resistance. This Ang II-induced insulin resistance was associated with significantly $(\mathrm{p}<0.05)$ decreased phosphorylation of Akt [both Ser ${ }^{473}$ (33\%) and $\mathrm{Thr}^{308}$ (38\%)] and AS160 $\mathrm{Thr}^{642}$ (30\%) in the red gastrocnemius muscle in situ (fig. 2). No difference between control and Ang II-treated groups was seen for p70 S6K Thr ${ }^{389}$ phosphorylation (data not shown). Interestingly, AMPK $\alpha \mathrm{Thr}^{172}$ phosphorylation was suppressed by $50 \%(\mathrm{p}<0.05)$ in the Ang II-treated group (fig. 2$)$. 


\section{CardioRenal Medicine}

Fig. 2. Effects of Ang II treatment on insulin-stimulated glucose transport activity in incubated soleus muscle and on critical signaling elements that impact insulin action in red gastrocnemius muscle frozen in situ. Values are means \pm SE for 3-6 muscles per group. Representative bands from the two groups are shown at the top. No difference between groups was seen for p70 S6K $\mathrm{Thr}^{389}$ phosphorylation (data not shown). $\mathrm{p}<0.05$ versus control group.

Fig. 3. Effect of AZIL-M on insulinstimulated glucose transport activity in incubated soleus muscle of Ang II-treated rats. Values are means \pm SE for 3 muscles per group.

\begin{tabular}{l|l}
\hline Cardiorenal Med 2013;3:154-164 \\
\hline DOI: $\underline{10.1159 / 000353155}$ & $\begin{array}{l}\text { @ 2013 S. Karger AG, Basel } \\
\text { www.karger.com/crm }\end{array}$ \\
\hline
\end{tabular}

Lastra et al.: The Novel Angiotensin II Receptor Blocker Azilsartan Medoxomil Ameliorates Insulin Resistance Induced by Chronic Angiotensin II Treatment

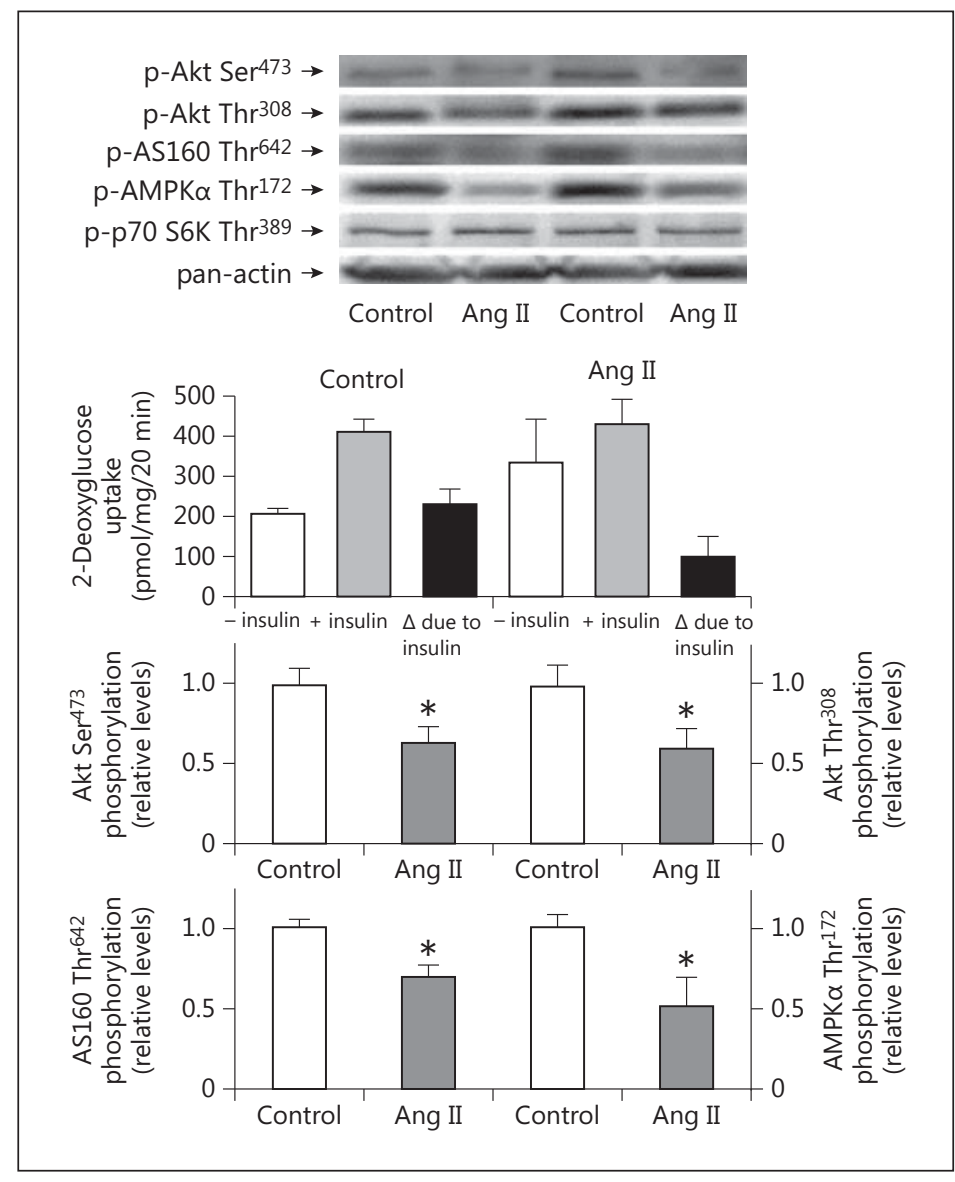

\section{Effect of AZIL-M Treatment on Ang II-Induced Insulin Resistance}

Co-treatment of Ang II-infused animals with AZIL-M led to an increase ( $\mathrm{p}=0.087)$ in insulin-stimulated glucose transport activity in the isolated soleus (fig. 3). AZIL-M treatment of the Ang II-infused rats caused several important changes in cellular signaling in red gastrocnemius in situ that may impact regulation of the glucose transport system. Increases in absolute phosphorylation of Akt $\operatorname{Ser}^{473}$ (81\%, p = 0.073) and Akt $\operatorname{Thr}^{308}(23 \%, \mathrm{p}<0.05)$ were observed in the AZIL-M-treated group, due at least in part to an increase $(38 \%, \mathrm{p}<0.05)$ in total Akt protein expression, although relative phosphorylation of Akt $\operatorname{Ser}^{473}$ tended $(\mathrm{p}=$ 
Fig. 4. Effect of AZIL-M on Akt signaling in red gastrocnemius muscle frozen in situ from Ang IItreated rats. Values are means \pm $\mathrm{SE}$ for 3 muscles per group. ${ }^{*} \mathrm{p}<$ 0.05 versus Ang II group.

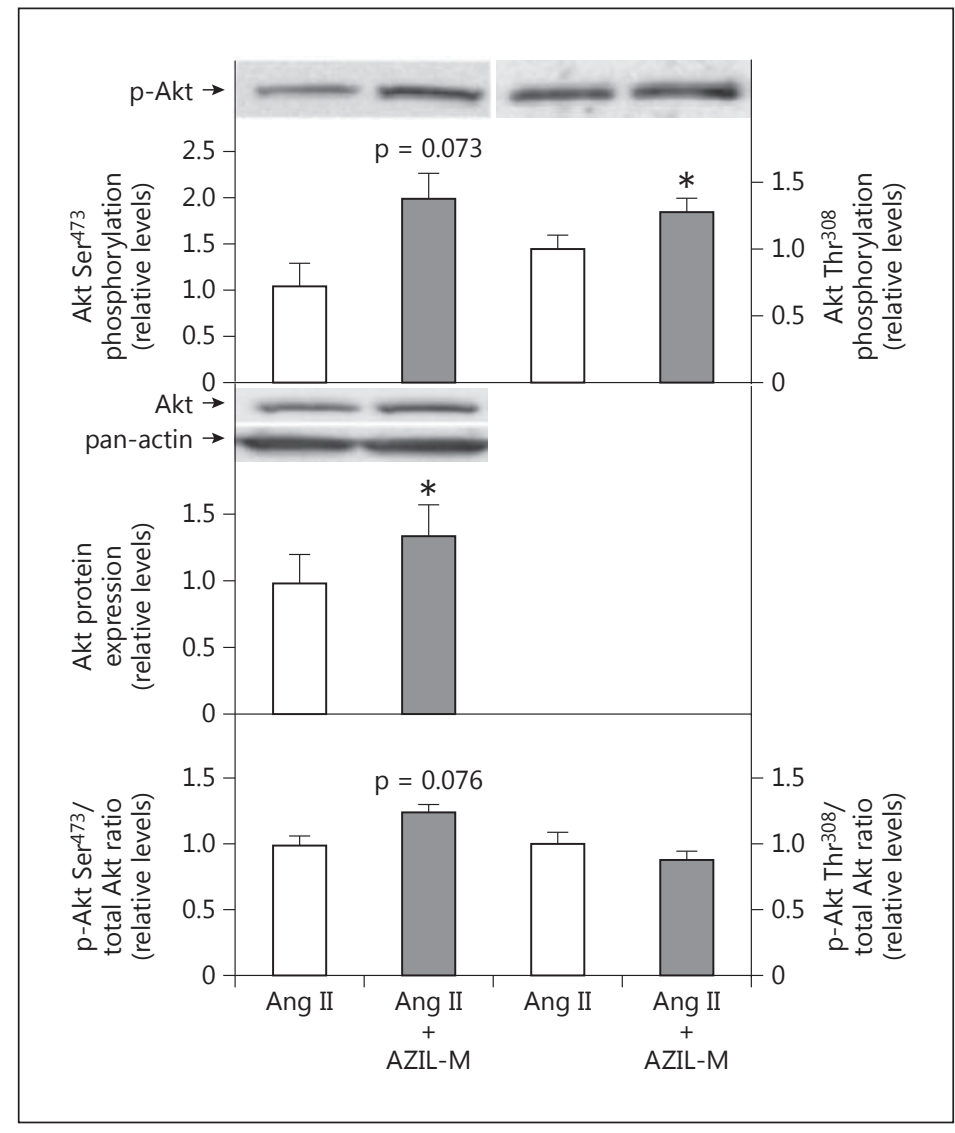

0.076 ) to be enhanced by AZIL-M treatment (26\%) (fig. 4). Likewise, AZIL-M treatment was associated with significant $(\mathrm{p}<0.05)$ increases in absolute AS160 phosphorylation $(42 \%)$ and AS160 protein expression (60\%), but not with relative AS160 phosphorylation (fig. 5). However, because these signaling factors were assessed in frozen red gastrocnemius muscle, they cannot be directly associated mechanistically with the alterations in insulin-mediated glucose transport activity in the red soleus muscle.

The effect of AZIL-M treatment on signaling factors that can modulate insulin signaling was also assessed. AZIL-M treatment was associated with a marked increase in absolute AMPK $\alpha$ Thr ${ }^{172}$ phosphorylation $(98 \%, \mathrm{p}<0.05)$ and a slight increase in AMPK $\alpha$ protein expression $(22 \%, \mathrm{p}<0.05)$ (fig. 6 , left panel). An increase in the relative phosphorylation of AMPK $\alpha(66 \%, p<0.05)$ was seen following AZIL-M treatment (fig. 6, left panel). In contrast, no effect of AZIL-M treatment was observed for absolute phosphorylation of p70 S6K1, while a tendency $(p=0.066)$ for a large increase in $\mathrm{p} 70$ S6K1 protein expression was seen in this group (fig. 6, right panel). This resulted in a decrease (51\%, though not statistically significant, $p=0.125$ ) in the relative phosphorylation of p70 S6K1 (fig. 6, right panel).

\section{Discussion}

A major finding of the present investigation is that the imidazole-based ARB AZIL-M can facilitate an enhancement of insulin-mediated glucose transport activity (fig. 3) in isolated soleus muscle of rats made hypertensive and insulin-resistant by chronic infusion of Ang II 
Lastra et al.: The Novel Angiotensin II Receptor Blocker Azilsartan Medoxomi Ameliorates Insulin Resistance Induced by Chronic Angiotensin II Treatment

Fig. 5. Effect of AZIL-M on AS160 signaling in red gastrocnemius frozen in situ from Ang II-treated rats. Values are means \pm SE for 3 muscles per group. $* \mathrm{p}<0.05$ versus Ang II group.

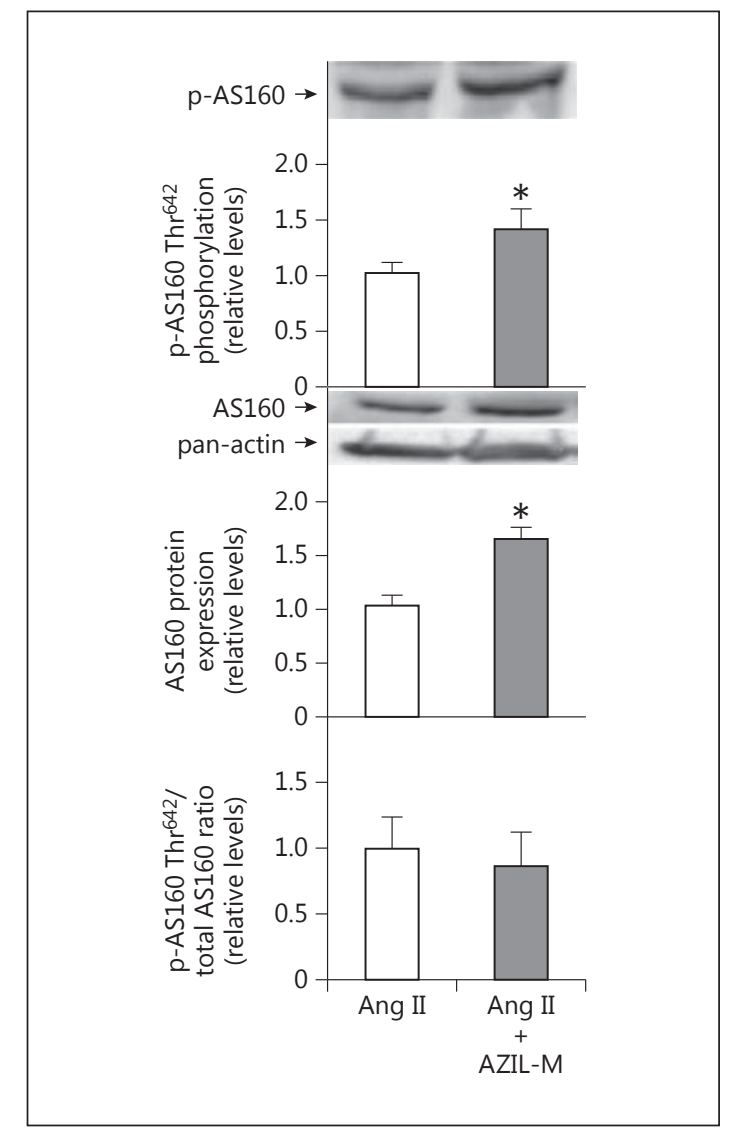

(fig. 1, 2). This metabolic improvement elicited by AZIL-M treatment occurred in concert with enhanced phosphorylation of several critical distal insulin signaling elements in red gastrocnemius muscle in situ, including Akt Ser ${ }^{473}$ (fig. 4), Akt Thr ${ }^{308}$ (fig. 4), and AS160 Thr ${ }^{642}$ (fig. 5), even in the face of lower circulating insulin levels (table 1 ). However, it should be emphasized once more that because these insulin signaling factors were measured only in frozen red gastrocnemius muscle, they cannot necessarily be directly related mechanistically to the improvement in insulin-mediated glucose transport activity in the incubated red soleus muscle. Moreover, AZIL-M treatment caused alterations in the phosphorylation state of some important modulators of insulin signaling in the frozen red gastrocnemius muscle, inducing a marked increase in AMPK $\alpha \mathrm{Thr}^{172}$ and a decrease in p70 S6K1 $\mathrm{Thr}^{389}$ (fig. 6). Therefore, the present investigation substantially extends recent studies indicating that AZIL-M improves whole-body insulin sensitivity in rodent models of hypertension, obesity, and insulin resistance $[22,23]$.

One plausible scenario accounting for these metabolic improvements elicited by AZIL-M in the Ang II-infused, insulin-resistant rats is the following. Treatment with this ARB, by reducing Ang II-dependent intracellular signaling in red skeletal muscle, would enhance Akt signaling [28], thereby increasing phosphorylation, and reducing the activity, of AS160, a Rab GTPase-containing protein also known as TBC1D4 [29, 30]. This inhibition of AS160 would allow more translocation of GLUT-4 protein in red muscle, leading to an enhanced rate of glucose transport activity. The increases in AMPK phosphorylation and activity associated with the AZIL-M treatment could also target AS160 [29, 30], further suppressing AS160 activity and promoting GLUT-4 translocation and glucose transport activity. 


\section{CardioRenal Medicine}

Fig. 6. Effect of AZIL-M on AMPK and p70 S6K signaling in red gastrocnemius muscle frozen in situ from Ang II-treated rats. Values are means \pm SE for 3 muscles per group. ${ }^{*} \mathrm{p}<0.05$ versus Ang II group.

\begin{tabular}{l|l}
\hline Cardiorenal Med 2013;3:154-164 \\
\hline DOI: $\underline{10.1159 / 000353155}$ & $\begin{array}{l}\text { @ 2013 S. Karger AG, Basel } \\
\text { www.karger.com/crm }\end{array}$ \\
\hline
\end{tabular}

Lastra et al.: The Novel Angiotensin II Receptor Blocker Azilsartan Medoxomil Ameliorates Insulin Resistance Induced by Chronic Angiotensin II Treatment

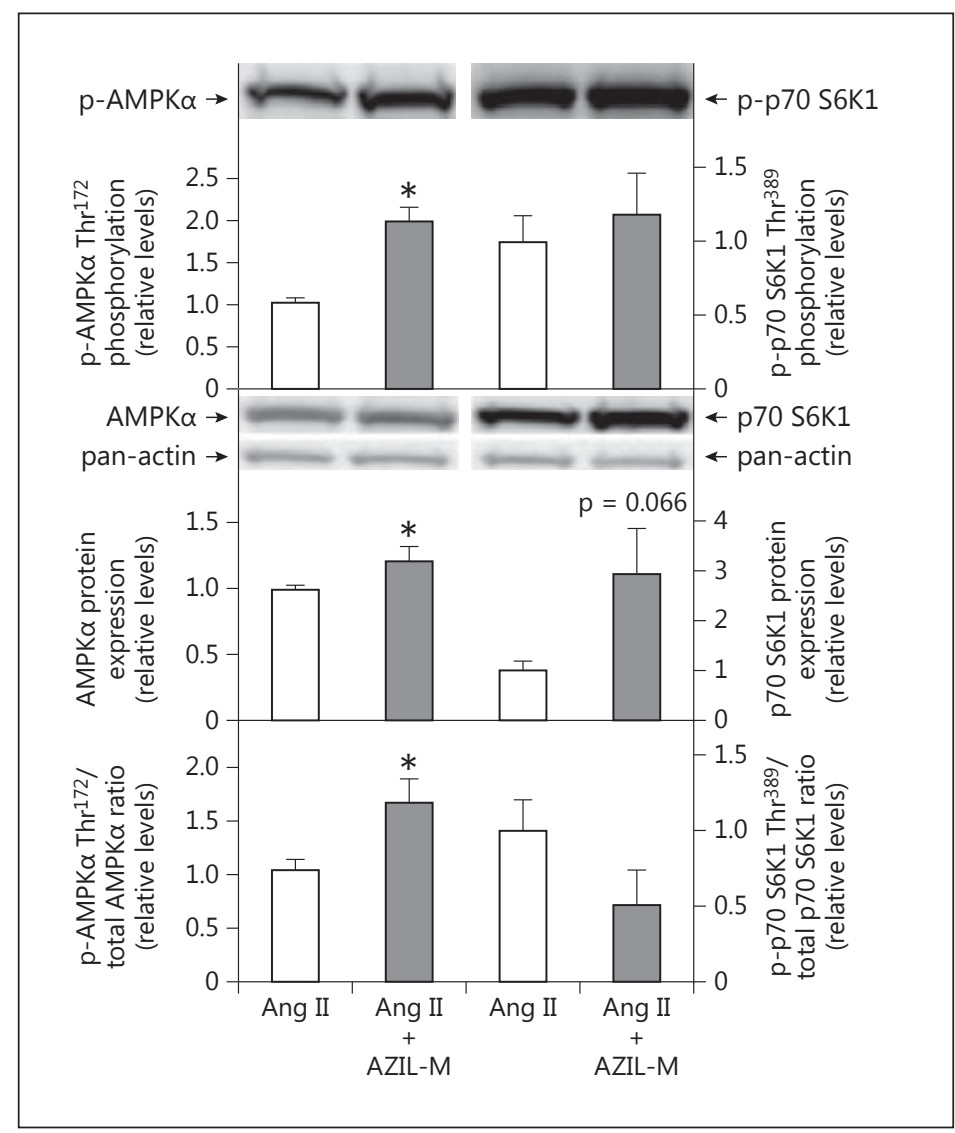

The potential role of p70 S6K1 in this context is compelling. p70 S6K1 is an important downstream effector of the mammalian target of rapamycin (mTOR) pathway. The activation of mTOR by upstream IRS-1/PI3K/Akt-dependent insulin signaling results in phosphorylation of specific serine and threonine residues (including $\mathrm{Thr}^{389}$ ) of p70 S6K1, leading to its activation, with downstream engagement of translational initiation and elongation factors [31].

Importantly, p70 S6K1 also can negatively regulate metabolic insulin signaling by facilitating serine phosphorylation of IRS-1, reducing its functionality and promoting the proteasomal degradation of this molecule [32-35]. In the present investigation, the suppression of p70 S6K1 by the AZIL-M treatment (fig. 6) could lessen the impact of this kinase to impair insulin signaling, leading to the enhanced Akt signaling observed under these conditions (fig. 4). Further investigation of the regulation of p70 S6K1 activity by the RAAS and its role as a negative modulator of insulin action in skeletal muscle is clearly warranted.

Excessive RAAS activation occurs in conditions such as obesity and hypertension, and has been linked to the development of insulin resistance and type 2 diabetes [reviewed in 3, 4, 13]. The present results in Ang II-treated rats are in agreement with previous studies indicating that specific increases in Ang II exposure are associated with decreased whole-body and skeletal muscle glucose disposal [9]. In addition, the results of the present study using the novel ARB AZIL-M are consistent with previous rodent model investigations from our research groups showing that interventions which suppress the RAAS, whether involving direct renin inhibition [11,12], ACE inhibition [13], ARB treatment [14-16], or mineralocorticoid receptor blockade [17], induce increases in skeletal muscle glucose transport activity due to enhanced Akt-dependent insulin signaling. 
The present results have importance in the context of human clinical and epidemiological investigations showing that RAAS blockade is associated with a reduction in the incidence of type 2 diabetes. Early clinical trials including the Heart Outcomes Prevention and Evaluation (HOPE), the Captopril Prevention Project (CAPP), the Candesartan in HeartFailure Assessment of Reduction in Mortality and Morbidity (CHARM) study, the Losartan Intervention for End Point Reduction (LIFE) study, and the Valsartan Antihypertensive Long-term Use Evaluation (VALUE) have reported a relative reduction in the incidence of type 2 diabetes of more than $20 \%[36,37]$. However, a limitation of these studies was that incidence of type 2 diabetes was not a primary outcome, and the findings were not confirmed in a large-scale trial designed specifically to evaluate the role of ACE inhibitors on new onset of type 2 diabetes in patients with impaired glucose tolerance. Nonetheless, RAAS blockade did have a positive impact on glucose homoeostasis, and patients treated with the ACE inhibitor ramipril exhibited a significantly higher rate of restoration of normoglycemia [18]. Recently, the Nateglinide and Valsartan Impaired Glucose Tolerance Outcomes Research (NAVIGATOR) trial showed that, in a population with impaired glucose tolerance and established risk factors for cardiovascular disease, treatment with the ARB valsartan was associated with a significant $14 \%$ reduction in the incidence of type 2 diabetes [38].

The present investigation does have some limitations. First and foremost, glucose transport activity measurements were made in the incubated red soleus muscle, whereas signaling measurements were made in the red gastrocnemius muscle in situ, preventing any direct mechanistic associations between these two data sets. Second, co-treatment of Ang II-infused Sprague-Dawley rats resulted in lower blood pressure relative to animals exposed to Ang II only (fig. 1). Blood pressure reduction is associated with decreased insulin resistance, making it difficult to make conclusions about the metabolic actions of AZIL-M independently of its blood pressure-lowering effects. However, we and others have demonstrated that RAAS blockade with renin inhibitors, ACE inhibitors, ARBs, and spironolactone exerts a positive effect on insulin sensitivity in skeletal muscle independently of changes in blood pressure in both rodents and humans $[11-13,17]$. Moreover, as glucose transport activity in skeletal muscle was assessed in vitro, this approach would not allow for the assessment of any potential effects of the Ang II and the ARB interventions on flow-dependent properties in the skeletal muscle tissues secondary to alterations in blood pressure. Finally, the present investigation does not address the potential impact of AZIL-M on metabolic regulation via the activation of PPAR- $\gamma$ and PPAR- $\delta$, as has been reported for this and other ARBs $[39,40]$.

In summary, the present study provides new data demonstrating that AZIL-M improves Ang II-induced insulin resistance of glucose transport activity in the incubated red soleus muscle and that this AZIL-M treatment enhances signaling via the Akt/AS160 axis in the red gastrocnemius muscle in situ, even in the face of lower circulating insulin concentrations. The results also suggest that these improvements in insulin signaling in the red gastrocnemius muscle following AZIL-M treatment may be related to activation of AMPK and suppression of p70 S6K1 signaling. Overall, the present investigation provides further support for targeting the RAAS to improve both hemodynamic and metabolic regulation in conditions of insulin resistance.

\section{Acknowledgements}

We gratefully acknowledge the technical support of Nathan T. Rehmer. Funding for this study was provided by a research grant from Takeda Pharmaceuticals (to V.G.D.), NIH R01 grants HL73101 and HL107910 and Veterans Affairs Merit System 0018 (to J.R.S.), and by the Guenther J. Dietze Foundation (to E.J.H.). 


\section{CardioRenal Medicine}

\begin{tabular}{l|l}
\hline Cardiorenal Med 2013;3:154-164 \\
\hline DOI: $\underline{10.1159 / 000353155}$ & $\begin{array}{l}\text { ( ) } 2013 \text { S. Karger AG, Basel } \\
\text { www.karger.com/crm }\end{array}$ \\
\hline
\end{tabular}

Lastra et al.: The Novel Angiotensin II Receptor Blocker Azilsartan Medoxomil Ameliorates Insulin Resistance Induced by Chronic Angiotensin II Treatment

\section{References}

1 Watson KE, Peters Harmel AL, Matson G: Atherosclerosis in type 2 diabetes mellitus: the role of insulin resistance. J Cardiovasc Pharmacol Therapeut 2003;8:253-260.

- 2 Kim JA, Montagnani M, Koh KK, Quon MJ: Reciprocal relationships between insulin resistance and endothelial dysfunction: molecular and pathophysiological mechanisms. Circulation 2006;113:1888-1904.

3 Cooper SA, Whaley-Connell A, Habibi J, Wei Y, Lastra G, Manrique C, et al: Renin-angiotensin-aldosterone system and oxidative stress in cardiovascular insulin resistance. Am J Physiol Heart Circ Physiol 2007; 293:H2009-H2023.

- 4 Henriksen EJ: Improvement of insulin sensitivity by antagonism of the renin-angiotensin system. Am J Physiol Regulatory Integrative Comp Physiol 2007;293:R974-R980.

5 Zhou MS, Schulman IH, Zeng Q: Link between the renin-angiotensin system and insulin resistance: implications for cardiovascular disease. Vasc Med 2012;17:330-341.

6 DeFronzo RA, Ferrannini E, Hendler R, Felig P, Wahren J: Regulation of splanchnic and peripheral glucose uptake by insulin and hyperglycemia in man. Diabetes 1983;32:32-45.

7 Baron AD, Brechtel G, Wallace P, Edelman SV: Rates and tissue sites of non-insulin- and insulin-mediated glucose uptake in humans. Am J Physiol Endocrinol Metab 1988;255:E769-E774.

$\checkmark 8$ Richey JM, Ader M, Moore D, Bergman RN: Angiotensin II induces insulin resistance independent of changes in interstitial insulin. Am J Physiol Endocrinol Metab 1999;277:E920-E926.

9 Ogihara T, Asano T, Ando K, Chiba Y, Sakoda H, Anai M, Shojima N, Ono H, Onishi Y, Fujishiro M, et al: Angiotensin II-induced insulin resistance is associated with enhanced insulin signaling. Hypertension 2002;40: 872-879.

10 Diamond-Stanic MK, Henriksen EJ: Direct inhibition by angiotensin II of insulin-dependent glucose transport activity in mammalian skeletal muscle involves a ROS-dependent mechanism. Arch Physiol Biochem 2010; 116:88-95.

11 Lastra G, Habibi J, Whaley-Connell AT, Manrique C, Hayden MR, Rehmer J, et al: Direct renin inhibition improves systemic insulin resistance and skeletal muscle glucose transport in a transgenic rodent model of tissue renin overexpression. Endocrinology 2009;150:2561-2568.

12 Marchionne EM, Diamond-Stanic MK, Prasonnarong M, Henriksen EJ: Chronic renin inhibition with aliskiren improves glucose tolerance, insulin sensitivity, and skeletal muscle glucose transport activity in obese Zucker rats. Am J Physiol Regul Integ Comp Physiol 2012;302:R137-R142.

13 Henriksen EJ, Jacob S: Angiotensin converting enzyme inhibitors and modulation of insulin resistance. Diabetes Obes Metab 2003;5:214-222.

-14 Henriksen EJ, Jacob S, Kinnick TR, Teachey MK, Krekler M: Selective angiotensin II receptor antagonism reduces insulin resistance in obese Zucker rats. Hypertension 2001;38:884-890.

15 Blendea MC, Jacobs D, Stump CS, McFarlane SI, Ogrin C, Bahtyiar G, et al: Abrogation of oxidative stress improves insulin sensitivity in the Ren-2 rat model of tissue angiotensin II overexpression. Am J Physiol Endocrinol Metab 2005;288:E353-E359.

16 Sloniger JA, Saengsirisuwan V, Diehl CJ, Kim JS, Henriksen EJ: Selective angiotensin II receptor antagonism enhances whole-body insulin sensitivity and muscle glucose transport in hypertensive TG(mREN2)27 rats. Metabolism 2005;54:1659-1668.

17 Lastra G, Whaley-Connell A, Manrique C, Habibi J, Gutweiler AA, Appesh L, et al: Low-dose spironolactone reduces reactive oxygen species generation and improves insulin-stimulated glucose transport in skeletal muscle in the TG(mRen2)27 rat. Am J Physiol Endocrinol Metab 2008;295:E110-E116.

18 Bosch J, Yusuf S, Gerstein H, Pogue J, Sheridan P, Dagenais G, et al: Effect of ramipril on the incidence of diabetes. N Engl J Med 2006;355:1551-1562.

19 Sharma AM, Engeli S: The role of renin-angiotensin system blockade in the management of hypertension associated with the cardiometabolic syndrome. J Cardiometabolic Syndr 2006;1:29-35.

20 Baker WL, White WB: Azilsartan medoxomil: a new angiotensin II receptor antagonist for treatment of hypertension. Ann Pharmacother 2011;45:1506-1515.

21 White WB, Weber MA, Sica D, Bakris GL, Perez A, Cao C, et al: Effects of the angiotensin receptor blocker azilsartan medoxomil versus olmesartan and valsartan on ambulatory and clinic blood pressure in patients with stages 1 and 2 hypertension. Hypertension 2011;57:413-420.

-22 Kusumoto K, Igata H, Ojima M, Tsuboi A, Imanishi M, Yamaguchi F, et al: Antihypertensive, insulin-sensitising and renoprotective effects of a novel, potent and long-acting angiotensin II type 1 receptor blocker, azilsartan medoxomil, in rat and dog models. Eur J Pharmacol 2011;669:84-93.

23 Zhao M, Li Y, Wang J, Ebihara K, Rong X, Hosoda K, et al: Azilsartan treatment improves insulin sensitivity in obese spontaneously hypertensive Koletsky rats. Diabetes Obes Metab 2011;13:1123-1129.

24 Zhou X, Ma L, HabibiJ, Whaley-Connell A, Hayden MR, Tilmon RD, et al: Nebivolol improves diastolic dysfunction and myocardial remodeling through reductions in oxidative stress in the Zucker obese rat. Hypertension 2010;55:880-888.

25 DeMarco VG, Ford DA, Henriksen EJ, Aroor AR, Johnson MS, Habibi J, et al: Obesity-related alterations in cardiac lipid profile and nondipping blood pressure pattern during transition to diastolic dysfunction in male db/db mice. Endocrinology 2013;154:159-171. 


\section{CardioRenal Medicine}

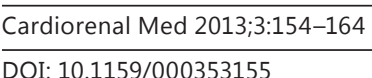

DOI: $10.1159 / 000353155$

Lastra et al.: The Novel Angiotensin II Receptor Blocker Azilsartan Medoxomil

Ameliorates Insulin Resistance Induced by Chronic Angiotensin II Treatment

-26 Henriksen EJ, Jacob S: Effects of captopril on glucose transport activity in skeletal muscle of obese Zucker rats. Metabolism 1995;44:267-272.

27 Hansen PA, Gulve EA, Holloszy JO: Suitability of 2-deoxyglucose for in vitro measurement of glucose transport activity in skeletal muscle. J Appl Physiol 1994;76:979-985.

28 Henriksen EJ, Diamond-Stanic MK, Marchionne EM: Oxidative stress and the etiology of insulin resistance and type 2 diabetes. Free Radic Biol Med 2011;51:993-999.

29 Fujii N, Jessen N, Goodyear LJ: AMP-activated protein kinase and the regulation of glucose transport. Am J Physiol Endocrinol Metab 2006;291:E867-E877.

30 Winder WW, Thomson DM: Cellular energy sensing and signaling by AMP-activated protein kinase. Cell Biochem Biophys 2007;47:332-347.

-31 Fraenkel M, Ketzinel-Gilad M, Ariav Y, Pappo 0, Karaca M, Castel J, et al: mTOR inhibition by rapamycin prevents $\beta$-cell adaptation to hyperglycemia and exacerbates the metabolic state in type 2 diabetes. Diabetes 2008;57:945-957.

-32 Khamzina L, Veilleux A, Bergeron S, Marette A: Increased activation of the mammalian target of rapamycin pathway in liver and skeletal muscle of obese rats: possible involvement in obesity-linked insulin resistance. Endocrinology 2005;146:1473-1481.

-33 Tremblay F, Brule S, Hee Um S, Li Y, Masuda K, Roden M, et al: Identification of IRS-1 Ser-1101 as a target of S6K1 in nutrient- and obesity-induced insulin resistance. PNAS 2007;104:14056-14061.

-34 Zhang J, Gao Z, Yin J, Quon MJ, Ye J: S6K directly phosphorylates IRS-1 on Ser-270 to promote insulin resistance in response to TNF- $\alpha$ signaling through IKK2. J Biol Chem 2008;283:35375-35382.

35 Kim JA, Jang HJ, Martinez-Lemus LA, Sowers JR: Activation of mTOR/p70S6 kinase by ANG II inhibits insulinstimulated endothelial nitric oxide synthase and vasodilation. Am J Physiol Endocrinol Metab 2012;302:E201E208.

-36 Lastra-Gonzalez G, Manrique C, Govindarajan G, Whaley-Connell A, Sowers J: Insights into the emerging cardiometabolic prevention and management of diabetes mellitus. Expert Opin Pharmacother 2005;6:22092221.

-37 Solski LV, Longyhore DS: Prevention of type 2 diabetes mellitus with angiotensin-converting-enzyme inhibitors. Am J Health Syst Pharm 2008;65:935-940.

-38 NAVIGATOR Study Group; McMurray JJ, Holman RR, Haffner SM, Bethel MA, Holzhauer B, Hua TA, et al: Effect of valsartan on the incidence of diabetes and cardiovascular events. N Engl J Med 2010;362:1477-1490.

-39 Kurtz TW: Beyond the class angiotensin-receptor-blocker profile. Nat Clin Pract Cardiovasc Med 2008;5(suppl 1):S19-S26.

40 Kajiya T, Ho C, Wang J, Vilardi R, Kurtz TW: Molecular and cellular effects of azilsartan: a new generation angiotensin II receptor blocker. J Hypertens 2011;29:2476-2483. 